SHORT REPORT

\title{
Focal nodular hyperplasia with concomitant hepatocellular carcinoma: a case report and clonal analysis
}

\author{
S-H Zhang, W-M Cong, M-C Wu
}

J Clin Pathol 2004;57:556-559. doi: 10.1136/¡cp.2003.012823

This report describes a hepatocellular carcinoma $(\mathrm{HCC})$ with concomitant focal nodular hyperplasia (FNH) in a 56 year old Chinese man. There were two well circumscribed tumours measuring $3 \times 2.5 \times 2 \mathrm{~cm}$ and $2 \times 1.5 \times 1.5 \mathrm{~cm}$. The larger mass was grey and soft with a small area of bleeding and necrosis and an intact capsule. The smaller mass was yellow and had no capsule. Clonal analysis was carried out to clarify the relation between the HCC and the adjacent $\mathrm{FNH}$. The clonal analysis was based on the methylation pattern of the polymorphic $\mathrm{X}$ chromosome linked androgen receptor gene (HUMARA). In FNH, after Hpall digestion, the allelic bands showed two well defined peaks. The intensity of the two peaks in the DNA from cirrhotic tissue did not differ significantly, consistent with a random pattern of $\mathrm{X}$ chromosome inactivation. However, in HCC, after Hpall digestion, the allelic bands differed significantly in intensity. Therefore, there was a typical polyclonal pattern of inactivation in $\mathrm{FNH}$ but the HCC was interpreted as being monoclonal.

$\mathrm{F}$ ocal nodular hyperplasia (FNH) is a benign tumour-like lesion of the liver. It is generally considered to be a hyperplastic response to an abnormal blood supply, rather than a neoplastic process. ${ }^{1}$ However, its nature and pathogenesis are still controversial. Although some reports have indicated an association between FNH and hepatocellular carcinoma (HCC), most authors do not consider there to be a pathogenetic correlation between them..$^{2-4}$ Here, we describe a patient with FNH and concomitant HCC, in whom we evaluated the clonality of both lesions using the HUMARA (methylation pattern of the polymorphic $\mathrm{X}$ chromosome linked androgen receptor gene) assay.

\section{CASE REPORT}

A 56 year old Chinese man, with a history of pernicious anaemia for several years, was noted to have hepatomegaly in a routine follow up. Laboratory data were as follows: aspartate aminotransferase, $48.7 \mathrm{U} /$ litre (normal, <34); alanine aminotransferase, $57.3 \mathrm{U} /$ litre (normal, $<36$ ); alkaline phosphatase, $143 \mathrm{U} /$ litre (normal, $<96$ ); and $\gamma$ glutamyltransferase, 161 IU/litre (normal, <96). Serum $\alpha$ fetoprotein was $126.3 \mu \mathrm{g} /$ litre (normal, <25). Serum hepatitis B virus surface antigen was positive and antihepatitis $\mathrm{C}$ virus antibody was negative. Imaging studies, including computed tomography (CT), abdominal ultrasound, and angiography, showed a heterogeneous, hypervascular enhancing mass in the right hepatic anterior lobe and medial portion with central necrosis. Another mass was slightly hypodense to the liver on unenhanced CT in the left hepatic lobe, and hyperdense to the liver during contrast enhanced CT. There were no tumour thrombi within the portal veins. After the liver tumour was resected, the serum $\alpha$ fetoprotein concentrations returned to within the normal range.

\section{MATERIAL AND METHODS}

Representative sections were taken from the surgical specimen, fixed in formalin, and embedded in paraffin wax. Histological sections were stained with haematoxylin and eosin.

\section{DNA extraction}

DNA was extracted from five to 10 paraffin wax embedded sections (each $5 \mu \mathrm{m}$ thick). When necessary, the area of interest was outlined and scraped with a clean scalpel blade. DNA extraction from lesional and non-lesional tissues was performed using the standard phenol/chloroform extraction and ethanol precipitation method. ${ }^{5}$ In brief, cirrhotic or cancer tissues were incubated with $2 \mathrm{ml}$ lysis/digestion buffer ( $1 \%$ sodium dodecyl sulfate, $1 \mathrm{mM}$ EDTA, $50 \mathrm{mM}$ Tris ( $\mathrm{pH} 8.5$ ), and $100 \mu \mathrm{g}$ proteinase $\mathrm{K} / \mathrm{ml}$ ) at $52^{\circ} \mathrm{C}$ for 16 hours. The digested lysate was subjected to two further extractions with an equal volume of chloroform/phenol/isoamyl alcohol $(24 / 25 / 1)$. After centrifugation, the DNA was precipitated from the aqueous phase by two volumes of cold absolute ethanol and collected with a glass rod. ${ }^{6}$ The DNA was purified further with RNase digestion and a two step phenol/chloroform extraction; it was then precipitated and collected as described above. The concentration of DNA was determined by both spectrophotometric and fluorometric methods, and it was stored at $4^{\circ} \mathrm{C}$.

\section{Assessment of clonality}

Clonality at the HUMARA locus was assessed by polymerase chain reaction (PCR), as described previously. ${ }^{7}$ Briefly, 500$1000 \mathrm{ng}$ of lesional or non-lesional DNA was digested overnight at $37^{\circ} \mathrm{C}$ in a $15 \mu \mathrm{l}$ reaction mixture containing 10 units of HpaII (Boehringer Mannheim GmbH, Meylan, France). For each specimen, a control sample containing only restriction enzyme buffer was run simultaneously. The restriction enzyme was then inactivated by heating at $95^{\circ} \mathrm{C}$ for 10 minutes.

For the PCR, $2 \mu \mathrm{l}$ of each DNA reaction mixture sample was added to $18 \mu \mathrm{l}$ of PCR reaction mixture containing $2 \mu \mathrm{l}$ of $10 \times$ PCR buffer, $1 \mu \mathrm{l}$ of $25 \mathrm{mmol} /$ litre $\mathrm{MgCl}_{2}, 2 \mu \mathrm{l}$ of each $\operatorname{dNTP}(200 \mu \mathrm{mol} /$ litre $), 1 \mu \mathrm{l}$ of each primer $(10 \mathrm{pmol}), 0.3 \mu \mathrm{l}$ of AmpliTaq Gold DNA polymerase (Perkin-Elmer Cetus, Foster City, California, USA), and $10.7 \mu \mathrm{l}$ of deionised $\mathrm{H}_{2} \mathrm{O}$. The sequences of the primers used for amplification of the HUMARA DNA were: 5'-GCTGTGAAGGTTGCTGTTCCTCAT3' (primer 1) and 5'-TCCAGAATCTG TTCCAGAGCGTGC-3' (primer 2). ${ }^{7}$ Primer 1 was labelled at the $5^{\prime}$ end with

Abbreviations: $\mathrm{CR}$, corrected ratio; $\mathrm{CT}$, computed tomography; $\mathrm{FNH}$, focal nodular hyperplasia; HCC, hepatocellular carcinoma; HUMARA, polymorphic $\mathrm{X}$ chromosome linked androgen receptor gene; PCR, polymerase chain reaction 
fluoroscein. Initial denaturation was performed for 10 minutes at $94^{\circ} \mathrm{C}$, followed by 30 cycles of 30 seconds at $94^{\circ} \mathrm{C}, 30$ seconds at $60^{\circ} \mathrm{C}$, and one minute at $72^{\circ} \mathrm{C}$, with a final extension at $72^{\circ} \mathrm{C}$ for seven minutes. All PCR samples were run in duplicate.

PCR products were purified twice in $70 \%$ alcohol after amplification. The injection mixture for each capillary was prepared by adding the following to each well of the injection plate: $2 \mu \mathrm{l}$ purified sample, $0.25 \mu \mathrm{l}$ ET400-R size standard, and $2.75 \mu \mathrm{l}$ loading solution (Amersham Pharmacia Biotech, Piscataway, New Jersey, USA). The injection mixtures were centrifuged and heat denatured for two minutes at $94^{\circ} \mathrm{C}$, immediately cooled, and placed on ice until ready to inject. Samples were electrophoresed on a MegaBACE-500 capillary array electrophoresis sequencer, and the fluorescent signals from the different sized alleles were recorded and analysed using Genetic Profiler version 2.1 software.

\section{Data interpretation}

For each sample, the peak intensities of the two alleles (alleles 1 and 2) were measured. A corrected ratio (CR) was first assessed by dividing the ratio (allele 1/allele 2) of the digested sample obtained after digesting DNA with HpaII by the ratio (allele $1 /$ allele 2 ) of the non-digested sample. The CR corrects for the preferential amplification of one allele, which might occur if the alleles differ greatly in length. A final clonality ratio for each tumour was determined by dividing the CR of the lesional DNA by the CR of the non-lesional DNA. This final clonal ratio corrects for the potential skewed lyonisation. The ratio is inverted if necessary to obtain a value up to 1. According to Paradis et al, ${ }^{7}$ a final ratio of 1.5 corresponded to the presence of $25 \%$ of clonal DNA in a polyclonal background. This value (1.5) was the threshold of sensitivity of the assay. Higher values indicated the presence of a significant number of clonal cells (arbitrarily defined threshold for clonality).

\section{RESULTS}

\section{Pathological findings}

Grossly, the resected liver tissue measured $7 \times 6 \times 4 \mathrm{~cm}$. There were two well circumscribed tumours measuring $3 \times 2.5 \times 2 \mathrm{~cm}$ and $2 \times 1.5 \times 1.5 \mathrm{~cm}$. The larger mass was grey and soft with a small area of bleeding and necrosis and an intact capsule. The smaller mass was yellow and had no capsule. An aberrant vessel penetrated through the grey part.

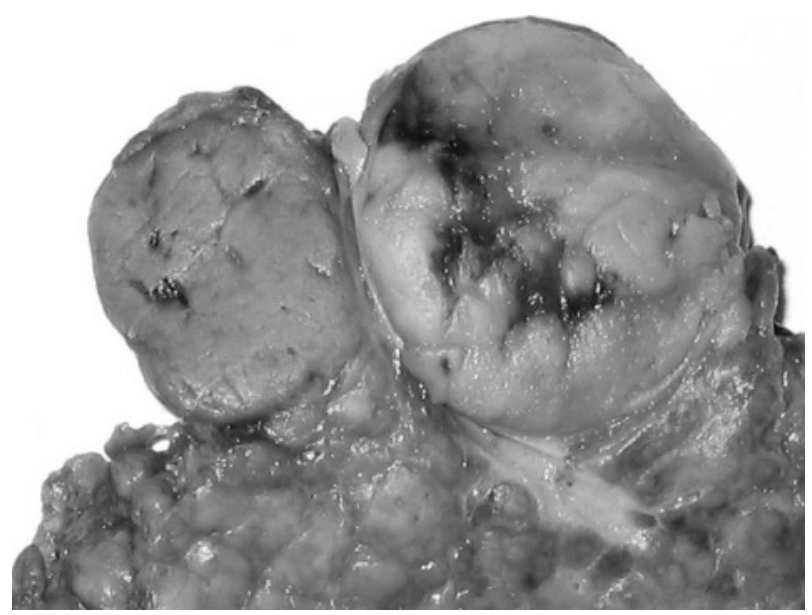

Figure 1 The liver tumour was composed of two different masses. The right mass was grey and soft with a small area of bleeding and necrosis. The left mass was yellow.

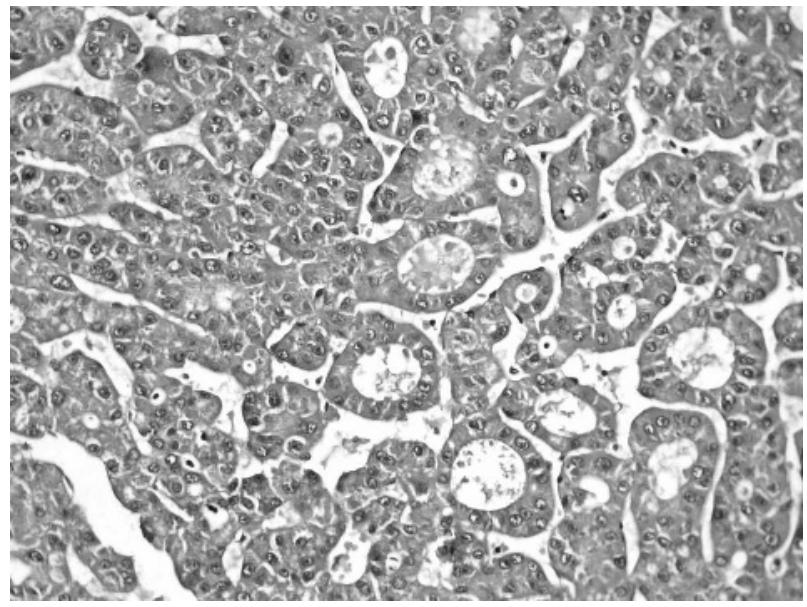

Figure 2 The yellow portion of the liver tumour was composed of large hyperplastic hepatocytes with short fibrous septa containing malformed vessels and bile ductules. Haematoxylin and eosin stain; original magnification, $\times 100$.

However, no central scar was found in the yellow part. The non-tumorous portion showed obvious cirrhotic nodularity (fig 1).

Microscopically, the yellow mass was composed of large hyperplastic hepatocytes with mild anisonucleosis. There were scattered fibrous septa and abnormal portal tracts with bile ductular proliferation and thick walled arterioles (fig 2). The nodule was completely or incompletely surrounded by circular or short fibrous septa. The hepatic plates were moderately thickened (two or three cells in thickness), but they usually alternated with single cell plates. They were composed of normal appearing hepatocytes, which could be focally atrophied, especially in the vicinity of sinusoidal dilatation, or rarely hypertrophied. Hepatocytes at the fibrous septal interface always showed some degree of ballooning. The grey mass was a classic HCC arranged in trabecular and acinar patterns with a small area of necrosis (fig 3). The tumour cells were growing in cords of variable thickness, which were separated by sinusoid-like blood spaces. The glandular or acinar structures were formed mostly by a single layer of tumour cells. A fibrous septum was present between

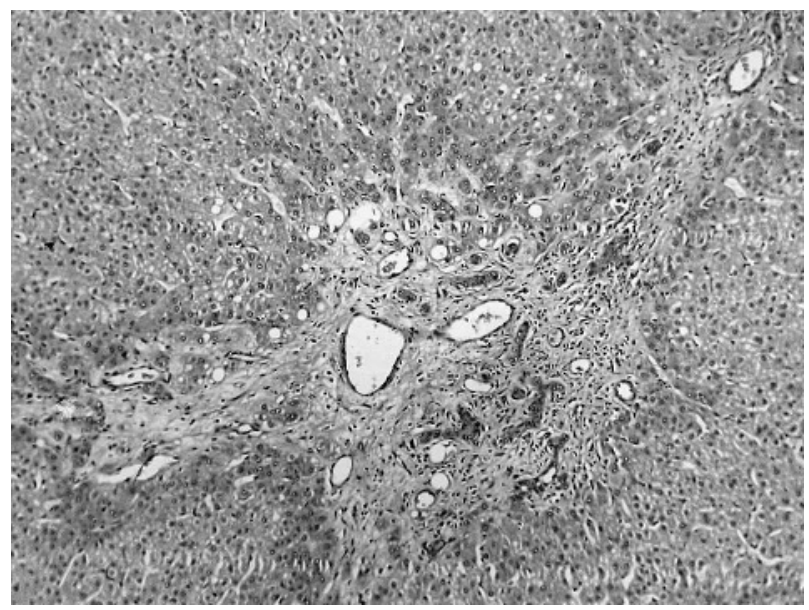

Figure 3 The grey portion of the liver tumour showed a classic hepatocellular carcinoma arranged in trabecular and acinar patterns. Haematoxylin and eosin stain; original magnification, $\times 200$. 


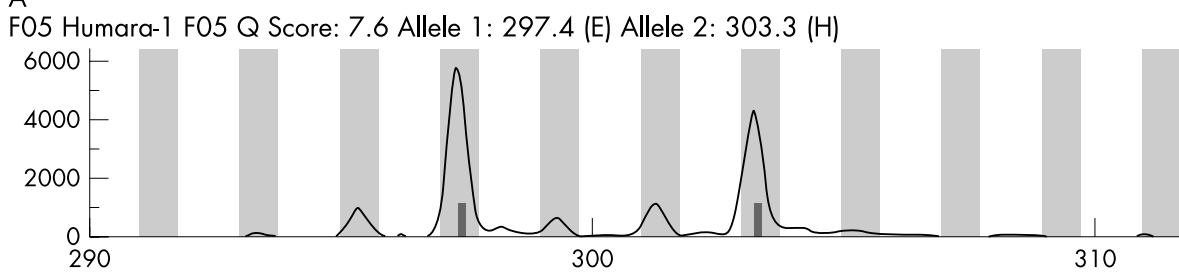

B

F06 Humara-1 F06 Q Score: 2.5 Allele 1: 297.4 (E) Allele 2: $303.3(\mathrm{H})$

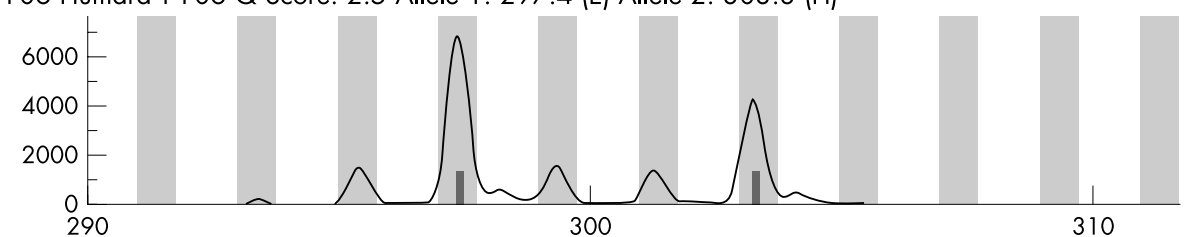

G01 Humara-1 G01 Q Score: 6.4 Allele 1: 297.5 (E) Allele 2: $303.3(H)$

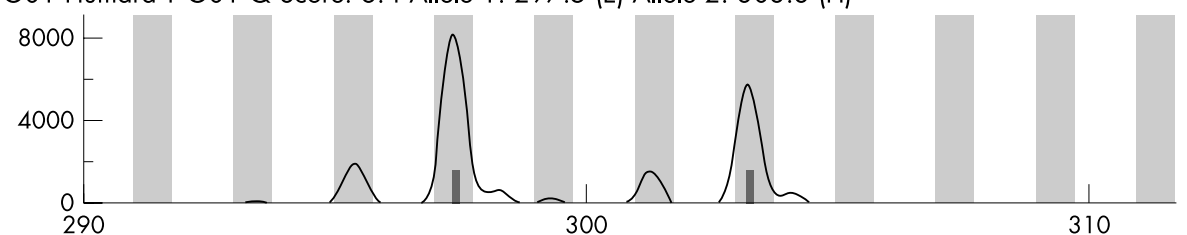

D

G02 Humara-1 G02 Q Score: 6.7 Allele 1: 297.5 (E) Allele 2: $303.3(\mathrm{H})$

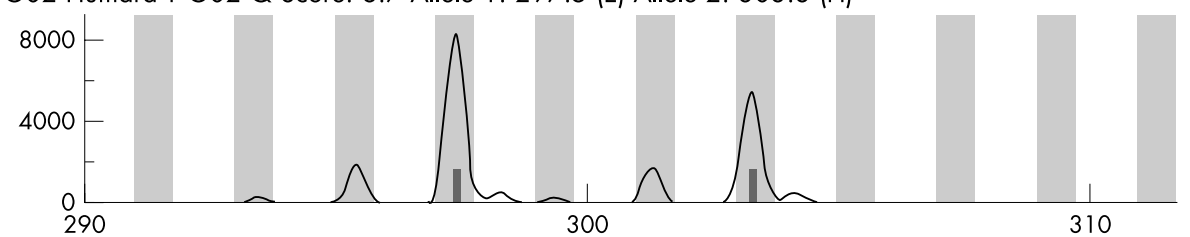

E

G05 Humara-1 G05 Q Score: 9.6 Allele 1: 297.4 (E) Allele 2: $303.3(\mathrm{H})$

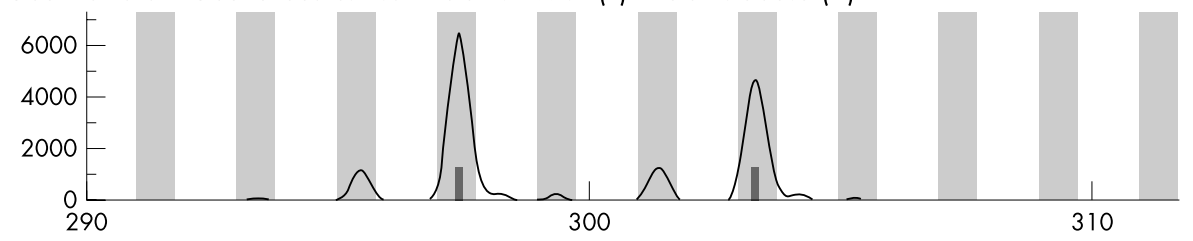

$\mathrm{F}$

G06 Humara-1 G06 Q Score: 1.0 Allele 1: $303.3(\mathrm{H})$

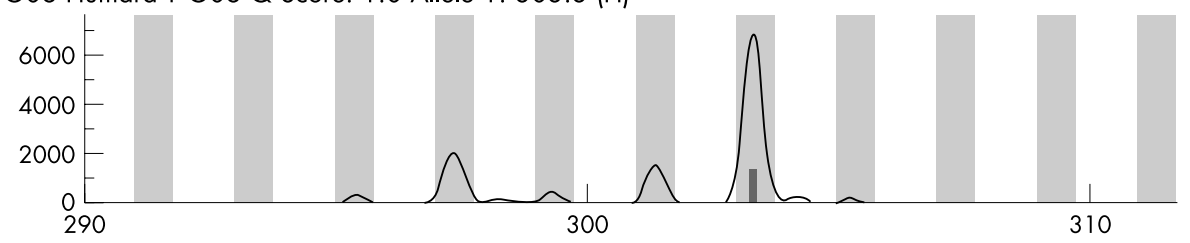

Figure 4 Clonal analysis. The results of the HUMARA assay in cirrhotic liver tissue (A) without digestion or (B) after Hpall digestion. Peaks 1 and 2 correspond to the two distinct alleles of the liver tissue. The results in focal nodular hyperplasia (FNH) (C) without digestion or (D) after Hpall digestion. DNA from cirrhotic liver tissue and FNH showed the same methylation pattern with and without Hpall digestion, consistent with a polyclonal pattern. The results in hepatocellular carcinoma (HCC) (E) without digestion or (F) after Hpall digestion. In HCC, a significant decrease of allele 2 was seen after Hpall digestion, consistent with a monoclonal pattern. the two liver tumours. The non-tumour part showed cirrhotic change.

\section{Clonal analysis}

Figure 4 shows the result of the clonal analysis. Without restriction enzyme digestion by HpaII, there were two allelic bands with equal intensity present, indicating that our patient's HUMARA gene was heterozygous and could be analysed. In the FNH lesion, after HpaII digestion, the allelic bands showed two well defined peaks, differing in size by two CAG repeats, corresponding to the two alleles of the HUMARA gene. The intensity of the two peaks in the DNA from the cirrhotic tissue did not differ significantly, consistent with a random pattern of $\mathrm{X}$ chromosome inactivation. It showed a typical polyclonal pattern of inactivation, with a final ratio value of 1.1. In HCC, after HpaII digestion, there was a significant reduction in the intensity of the allelic bands. Thus, the HCC was interpreted as being monoclonal.

\section{DISCUSSION}

The liver tumour described here comprised two different parts with different histological features. The yellow part was composed of large hyperplastic hepatocytes with abnormal nodular architecture, malformed vessels, and bile ductule proliferation. Although the central scar was absent in this mass, the lesion fulfilled the morphological diagnostic criteria of a FNH. ${ }^{1}$ The grey mass was a classic HCC. Associations between HCC and FNH have rarely been described. To our knowledge, two were fibrolamellar variants of HCC and one was a classic HCC. ${ }^{2-4}$ 


\section{Take home messages}

- We describe a hepatocellular carcinoma (HCC) with concomitant focal nodular hyperplasia (FNH) in which we undertook clonal analysis of the HUMARA gene

- The FNH showed a typical polyclonal pattern of inactivation but the HCC showed a monoclonal pattern

- These results do not support the notion that the HCC was the result of malignant transformation of the $\mathrm{FNH}$, which may have developed secondary to the feeding artery of the $\mathrm{HCC}$

The nature of FNH is still not clear. Chen and colleagues ${ }^{8}$ used comparative genomic hybridisation to evaluate genomic changes in hepatic adenoma, FNH, and HCC. The results showed that the overall genomic abnormalities in hepatic adenoma and FNH were much less obvious than those in HCC. The comparative genomic hybridisation alterations found in FNH did not coincide with the common genomic lesions of cancerous HCC. Paradis and colleagues ${ }^{7}$ reported 13 FNHs, which showed a typical polyclonal pattern of inactivation, with a mean final ratio value of 1.1, strongly supporting the hypothesis that FNH is a reactive polyclonal process showing random $\mathrm{X}$ chromosome inactivation. However, conflicting results were reported by other authors ${ }^{4} 9$ using the same method. Chen and colleagues ${ }^{4}$ reported that the inactivated alleles in FNH and HCC were not identical. These results indicated that the HCC and adjacent FNH probably developed through clonal expansion of two different clones.

\section{"Associations between hepatocellular carcinoma and focal nodular hyperplasia have rarely been described"}

Our results also showed a typical polyclonal pattern of inactivation in the $\mathrm{FNH}$, and a monoclonal pattern in the
HCC. Therefore, our study did not support the notion that the HCC was the result of malignant transformation of the FNH. It is possible that the FNH developed secondary to the feeding artery of the HCC in our case.

\section{Authors' affiliations}

Shu-Hui Zhang, Wen-Ming Cong, Meng-Chao Wu, Department of Pathology, Eastern Hepatobiliary Surgery Hospital, Second Military Medical University, Shanghai 200438, China

Correspondence to: Dr S-H Zhang, Department of Pathology, Eastern Hepatobiliary Surgery Hospital, Second Military Medical University,

Shanghai 200438, China; zhangshuhui100@sohu.com

Accepted for publication 26 September 2003

\section{REFERENCES}

1 Nguyen BN, Flejou JF, Terris B, et al. Focal nodular hyperplasia of the liver: a comprehensive pathologic study of 305 lesions and recognition of a new histologic form. Am J Surg Pathol 1999;23:1441-54

2 Saul SH, Titelbaum DS, Gansler TS, et al. The fibrolamellar variant of hepatocellular carcinoma: its association with FNH. Cancer, 1987; 60:3047-55

3 Saxena R, Humphreys S, Williams R, et al. Nodular hyperplasia surrounding fibrolamellar carcinoma: a zone of arterialized liver parenchyma. Histopathology 1994;25:275-8.

4 Chen TC, Chou TB, Ng KF, et al. Hepatocellular carcinoma associated with focal nodular hyperplasia. Report of a case with clonal analysis. Virchows Arch 2001:438:408-11.

5 Sood AK, Buller RE. Genomic instability in ovarian cancer: a reassessment using an arbitrarily primed polymerase chain reaction. Oncogene 1996; 13:2499-504.

6 Weber JL, May PE. Abundant class of human DNA polymorphism which can be typed using the polymerase chain reaction. Am J Hum Genet 1989;44:388-96.

7 Paradis V, Laurent A, Flejou JF, et al. Evidence for the polyclonal nature of focal nodular hyperplasia of the liver by the study of X-chromosome inactivation. Hepatology 1997;26:891-5.

8 Chen YJ, Chen PJ, Lee MC, et al. Chromosomal analysis of hepatic adenoma and focal nodular hyperplasia by comparative genomic hybridization. Genes Chromosomes Cancer 2002;35: 138-43.

9 Gaffey MJ, lezzoni JC, Weiss LM. Clonal analysis of focal nodular hyperplasia of the liver. Am J Pathol 1996;148:1089-96. 


\section{PostScript}

\section{CORRESPONDENCE}

If you have a burning desire to respond to a paper published in the Journal of Clinical Pathology, why not make use of our "rapid response" option?

Log on to our website (www.jclinpath. com), find the paper that interests you, and send your response via email by clicking on the "eletters" option in the box at the top right hand corner.

Providing it isn't libellous or obscene, it will be posted within seven days. You can retrieve it by clicking on "read eletters" on our homepage.

The editors will decide as before whether to also publish it in a future paper issue.

\section{Cancer stem cell theory: pathologists' considerations and ruminations about wasting time and wrong evaluations}

The genomic revolution has changed the role of the pathologist. In daily practice, our work is no longer limited to reaching a correct diagnosis and we are asked to answer questions about the patient's prognosis and treatment options through the evaluation of selected molecular targets (such as erbB2 for breast cancer) in tumour specimens. Thus, we have acquired a major role in the translation of novel gene findings from experimental model systems to their clinical application.

There is overwhelming evidence that only a subset of cells within a tumour clone, referred to as cancer stem cells, are tumorigenic and possess the metastatic phenotype. The recent identification of human breast cancer initiating cells by Al-Hajj and colleagues $^{2}$ provided a major step forward in this field. With this knowledge, the stem cell compartment should represent the selected target for tumour eradication.

As pathologists we would like to share some considerations and ruminations about this scenario.

Currently, tissue microarray analysis generates gene profiles capable of differentiating tumours with different biological behaviours. ${ }^{3}$ However, this screening method is conducted on heterogeneous tumour tissue samples containing a mixture of non-neoplastic cells, non-tumorigenic cancer cells, and cancer stem cells. Similarly, until now, we have evaluated the immunohistochemical expression of a molecular marker in the bulk of the tumour, considering it as relatively homogeneous.

What is the clinical relevance of these results? Although new therapeutic approaches based on these studies have modified the prognosis of some neoplasms, ${ }^{4}$ conflicting results are still seen with many other tumours. ${ }^{5}$ We should start to feel worried about the value of the information retrieved from this type of tumour analysis.
The few cancer stem cells and the large number of cells constituting the tumour are morphologically similar but functionally heterogeneous. It is likely that we are still evaluating the main population of tumour cells, which are not cancer stem cells, and are thus probably wasting time and loosing essential treatment information. It is unlikely that gene expression profiles obtained using the currently available methods reflect those of the tumour stem cell population, which forms only $0.1-2 \%$ of the whole tissue sample. ${ }^{126}$

The cancer stem cell hypothesis has started a new era in cancer research. Tumours contain functionally different subpopulations of cells. However, unique gene expression profiles are generated by current methods of evaluation. Probably, when the isolation and molecular characterisation of cancer stem cells from primary tissue becomes possible, the role of pathologists will change again. Collaboration between researchers and pathologists will be more widely practised and we will be able to rise to the next challenge; namely, assessing the prognosis of a patient from only one of 5000 tumour cells in a tissue sample.

P Nuciforo

Fimo-Firc Institute of Molecular Pathology Via Adamello 16, Milano 20139, Italy nuciforo@ifom-firc.it

F Fraggetta

Azienda Ospedaliera Cannizzaro, Via Messina, 829, Catania 95126 , Italy

\section{References}

1 Reya T, Morrison SJ, Clarke MF, et al. Stem cells, cancer, and cancer stem cells. Nature 2001:414:105-11.

2 Al-Haii M, Wicha MS, Benito-Hernandez A, et al. Prospective identification of tumorigenic breast cancer cells. Proc Natl Acad Sci U S A 2003;100:3983-8.

3 Van de Vijuer MJ, He YD, van't Veer $\sqcup$, et al. A gene-expression signature as a predictor of survival in breast cancer. N Engl I Med 2002;347:1999-2009.

4 Orr MS, Scherf U. Large-scale gene expression analysis in molecular target discovery. Leukemia 2002;16:473-7.

5 Carney DN. Lung cancer-time to move on from chemotherapy. N Engl I Med 2002;346:126-8.

6 Dick JH. Breast cancer stem cells revealed. Proc Natl Acad Sci U S A 2003;100:3547-9.

\section{Public opinion on the use of tissue samples}

I read with interest and increasing concern the paper by Goodson and Vernon, " "A study of public opinion on the use of tissue samples from living subjects for clinical research". The paper demonstrates that the use of a vaguely worded and ambiguous questionnaire leads to misleading results. A few of the problems with the questions may be taken individually:

(1) "Would you be happy for pieces of any of the following body tissues or organs to be used in clinical research? (Eyes, lung, heart, tissue from head and neck, embryo, brain, ovary, testes, bone, and breast.)"
The question could refer to postmortem tissue and the choice of organs is (as the authors confess) deliberately "emotional", with no insight into every day pathological services. Heart, brain, and eyes are not exactly common surgical specimens, whereas embryos are subject to special guidelines. Surely, this question is almost designed to make the patient believe it refers to postmortem organs? The use of subjective words such as "happy" is extremely unhelpful. "Are you happy to vote Labour?" would not, for example, be acceptable in a comparable political survey!

(2) "What kind of research would you be happy for your tissues to be used for? (Cancer research, testing medicines, genetic cloning, general knowledge of body tissues, genetic research for diagnosis or treatment of, for example, Down's syndrome.)"

Again scientific imprecision exists, because the writers of the questionnaire appear not to understand that these fields are interdependent. In particular, the lack of public understanding of cloning has caused them to reject this field, with no idea that this may include tissue culture or polymerase chain reaction

(3) "Would you want to be informed if your tissues were to be stored beyond the time required for diagnosis?"

This question seems to show no knowledge of the necessity for longterm storage of samples after diagnosis. Tissue retention for medicolegal, audit, clinical governance, and comparison with later samples has been ignored. No explanation has been given to the patients of why this is in their best interests.

(4) "Would you be happy to give consent for a child's tissues to be used for scientific research?"

Apart from the obvious flaw that it has not been stated whose child is being talked about, again the question appears almost deliberately ambiguous and could be taken to refer to postmortem tissue. Apparently, the designers of the questionnaire are interested in "scientific research" on children's tissues, whereas in adults in question $l$ it is only "clinical research".

(5) "Would you be happy to give consent for your tissues to be used to teach medical students?"

The word happy is used again, in addition to a lack of explanation of how the tissues are "used", and the vital role of histology in teaching medical students and pathology trainees.

I suggest to the authors that their survey, in contrast to all other studies, shows that patients were unwilling to donate their tissues because they were presented with a poorly designed, misleading survey.

D M Berney

Department of Pathology, St Bartholomew's Hospital, West Smithfield, London EClA 7BE, UK; danberney@hotmail.com 


\section{Reference}

1 Goodson ML, Vernon BG. A study of public opinion on the use of tissue samples from living subjects for clinical research. J Clin Pathol 2004:57:135-8.

\section{Authors' response}

We are grateful for the opportunity to respond to Dr Berney's letter. The questionnaire used in our study was piloted on a similar group of respondents. The patient information leaflet and consent form given and explained before completion of the questionnaire made it clear that we were only concerned with tissue donated by living subjects for research and did not refer to the use of postmortem specimens or tissue or organs for transplantation. In addition, all respondents were given the opportunity to ask questions before completing the questionnaire if they were unsure of the meaning of any questions.

We imagine that many of the research fields are interdependent, although the general public may not be aware of this. Our study did not attempt to explain why respondents answered questions in any particular way, but it shows that people may or may not be willing to donate different types of tissue for different types of research. This may be because of a lack of understanding of the clinical and laboratory techniques used in research, but we have not attempted to prove this in our study.

We agree that no explanation was given to respondents (who were not patients) about the benefits of retention of tissue samples; this would have biased the response.

Dr Berney says that our question surrounding consenting for donation of a child's tissue for research is flawed because it does not explain whose child we are discussing. Our pilot study demonstrated that the phrase "your child" eliminated responses from childless adults, adults with children over 16 years of age who were able to consent for themselves, and individuals who had children, but for various reasons were no longer the guardians of such children. The question merely attempted to identify whether or not there was some reluctance by adults to consent for children.

Our research showed a snap shot of public attitudes to tissue donation from living subjects for clinical research and offers no more than an indicator of public attitude, and like most research requires further qualification.

We are grateful to Dr Berney for his comments because they open up the debate on whether the public accepts tissue donation for research purposes. To restore public confidence in the medical profession and research in general, it is crucial for the profession to take account of public perceptions and to understand the nature of the explanations that are required

M L Goodson, B G Vernon School of Population and Health Science, University of Newcastle, Newcastle upon Tyne, NE2 4HH M.L.Goodson@ncl.ac.uk

\section{Limitations of the Wilcoxon matched pairs signed ranks test for comparison studies}

We read the short report by Ellis et al with interest. ${ }^{1}$ However, we are unsure whether they have adequately proved that no significant difference was detected between the two outlined storage methods.

The hypothesis evaluated with the Wilcoxon matched pairs signed ranks test is whether or not the median of the difference scores equals zero. Let us consider the situation of $x$ measurements tending to exceed $y$ measurements in the low range and vice versa in the high range, with similar values in the mid range. Such results may have a median of the difference scores of approximately zero; that is, there might be no significant differences by the Wilcoxon matched pairs signed ranks test, although there would be differences by linear regression (Deming or Passing-Bablok) and/or difference plots.

However, this short report ${ }^{1}$ lacks both a regression equation (proportional and constant error) and difference plots. Therefore, we believe that although the IgG anti-rubella activity in frozen serum stored in primary gel separation tubes may not be significantly different from that stored frozen in secondary tubes, this study did not sufficiently prove this. We recommend, in line with others, ${ }^{2}$ that difference plots ${ }^{3}$ are used for such comparative studies and that such studies are put into a clinical context. ${ }^{34}$

P J Twomey

Department of Clinical Biochemistry, The Ipswich Hospital, Heath Road, Ipswich IP4 5PD, UK taptwomey@aol.com

A Viljoen

Department of Clinical Biochemistry, Royal Infirmary of Edinburgh, Room S6114 Level 2, 51 Little France Crescent, Edinburgh EH16 4SA, UK

\section{References}

1 Ellis V, Charlett A, Bendall R. A comparison of lgG anti-rubella activity in frozen serum stored in primary gel separation tubes or secondary tubes. $J$ Clin Pathol 2004;57:104-6.

2 Hollis S. Analysis of method comparison studies. Ann Clin Biochem 1996:33:1-4.

3 Bland JM, Altman DG. Statistical methods for assessing agreement between two methods of clinical measurement. Lancet 1986;i:307-10.

4 Fraser CG, Kallner A, Kenny D, et al. Introduction: strategies to set global quality specifications in laboratory medicine. Scand J Clin Lab Invest 1999;59:477-8

\section{BOOK REVIEWS}

\section{Basic Pathology: An Introduction to the Mechanisms of Disease}

Lakhani S R, Dilly S A, Finlayson C J, et al. (£22.99.) Arnold, 2003. ISBN 0340810017.

With the new "integrated" undergraduate medical curriculum being adopted by medical schools in many countries, there is an ever increasing need for an appropriate basic pathology textbook. The authors have produced a book which is based on the principles and objectives of the integrated curriculum. Consequently, it is an ideal basic pathology textbook for students in the integrated medical curriculum.

The book has a novel approach to basic pathology, which is different from the standard basic pathology textbooks. There are four parts: "Introduction-what is a disease?", "Defence against disease", "Circulatory disorders", and "Disorders of cell growth". Each part consists of a variable number of chapters containing several unique learning aids.

The material is presented in a format that is easy to read and can be read at leisure. In accordance with the integrated curriculum, some material is presented by using clinical cases-for example, myocardial infarction, breast lump, and prostatic hyperplasia, among others. Innovative additions are the excellent cartoons, selected "key facts", "dictionary box", and "small print". The cartoons are well illustrated, extremely apt, and informative. There is also a selection of relevant tables that complement the text. The inclusion of appropriate colour diagrams, photomicrographs, and macroscopic pathology images aids the text. Clinicopathological case studies are used as a tool to facilitate the integration of pathology with clinical medicine. At the end of each part, there is a selection of questions covering core material with answers and cross references.

There are six colour coded theme maps that cover the four main pathology disciplineshistopathology, haematology, immunology, and microbiology - and two additional overview themes-science and disease and patient and disease.

The authors have produced a remarkable book, which deals with a difficult but important subject in a user friendly manner. The book ought to be prescribed reading for undergraduate students in the new integrated medical curriculum.

D Govender

\section{The Cytology of Soft Tissue Tumours}

Akerman M, Domanski H A. (€110.00.) Karger, 2003. ISBN 380557597.

Åkerman's and Domanski's text The Cytology of Soft Tissue Tumours from the Monographs in Clinical Cytology series is a beautifully illustrated, well referenced and written treatise on the interpretation of fine needle aspirations (FNAs) of these lesions. The text starts with a brief overview of the FNA of soft tissue tumours including accuracy, pitfalls, complications, and a discussion of the aspiration technique itself, with application of ancillary studies. This is followed by a concise review of the specific entities following standard histogenetic organisation. With each major entity, the salient cytological features and differential diagnostic considerations are clearly listed, with comments on the potential pitfalls admixed with helpful hints, providing a practical approach to the diagnosis of the lesions. The final chapter summarises in tabular form the salient diagnostic features and results of ancillary studies of the various entities in groupings based on a pattern recognition approach. Illustrations abound and include air dried May-Grünwald-Giemsa, in addition to alcohol fixed haematoxylin and eosin or occasionally Papanicolaou stained cytological preparations. Little criticism of this text can be found and there is no question that this book should be in the library of those interpreting FNAs of soft tissue lesions.

S Boerner 


\section{CALENDAR OF EVENTS}

Full details of events to be included should be sent to Maggie Butler, Technical Editor JCP. The Cedars, 36 Queen Street, Castle Hedingham, Essex CO9 3HA, UK; email: maggie.butler2@btopenworld.com

\section{Practical Pulmonary Pathology}

27-30 July, 2004, Brompton Hospital, London, UK

Further details: Professor B Corrin, Brompton Hospital, London SW3 6NP, UK. (Tel: +44 (0)20 7351 8420; Fax: +44 (0)20 7351 8293; Email: b.corrin@ic.ac.uk)

\section{ACP Management Course for} Pathologists, 2004

8-10 September 2004, Hardwick Hall Hotel, Sedgefield, County Durham, UK

Further details: V Wood, ACP Central Office, 189 Dyke Road, Hove, East Sussex BN3 ITL, UK. (Tel: +44 (0) 1273 775700; Fax: +44 (0) 1273 773303; Email: Jacqui@pathologists.org.uk)
Combined Adult and Congenital Cardiovascular Pathology Course

8-10 November 2004, Imperial School of Medicine, National Heart and Lung Institute, London, UK

Further details: Short Course Office, National Heart and Lung Institute, Dovehouse Street, London SW3 6LY, UK (Tel: +44 (0)20 7351 8172; Fax: +44 (0)20 7351 8246; Email: shourtcourse.NHLI@ IC.AC.UK)

Asian Pacific Association for Study of the Liver Biennial Conference

11-15 December 2004, New Delhi, India Further details: Dr V Malhotra (General Secretary) or Dr P Sakhuja (Treasurer and Pathology Coordinator), Room 325, Academic Block, Department of Pathology, GB Pant Hospital, New Delhi 110002 India. (Tel: +91 11 23237455; Email: welcome@apaslindia2004.com; Website: www.apaslindia2004.com)

\section{CORRECTIONS}

MUC1 and MUC2 in pancreatic neoplasia. E Levi, D S Klimstra, N V Adsay, A Andrea, O Basturk. J Clin Pathol 2004;

57:456-62. The order of the authors should be E Levi, D S Klimstra, A Andrea, O Basturk, $\mathrm{N}$ V Adsay.

Urinary catecholamines and metabolites in the immediate postoperative period following major surgery. Dr A A Syed, $\mathrm{H}$ A Wheatley, $\mathrm{M} \mathrm{N}$ Badminton, et al. $J$ Clin Pathol 2004;57:548-50. The first author's name should be A A Syed.

Focal nodular hyperplasia with concomitant hepatocellular carcinoma: a case report and clonal analysis. S-H Zhang, W-M Cong, M-C Wu. J Clin Pathol 2004 57:556-9. The image shown in fig 2 should have been fig 3 and vice versa. 